\title{
SUPER-, THOMAS- JA HIENOFOSFAATIN VAIKUTUKSESTA MUTASUOLLA
}

\author{
MAURi TAKala \\ Suoviljelysyhdistys, Leteensuon koeasema
}

Saapunut 1. 12, 1960

Suoviljelykset ovat tunnetusti fosforiköyhiä. Niiden lannoitukseen käytetään useammanlaisia fosfaattilannoitteita. Seuraavassa käsitellään erään Leteensuon koeaseman mutasuolle perustetun pitkäaikaisen fosfaattilannoituskokeen tuloksia.

\section{Koemaa ja koesunnitelma}

Yksityiskohtaisen kasvipeitekuvauksen suoalueesta on tehnyt LiNDBERG (2). Suon geologista puolta on selvittänyt RiNDELL (5). Koealueen turve on melko hyvin maatunutta metsäsaraturvetta. Turvekerroksen paksuus on yli $1 \mathrm{~m}$.

Alue on raivattu viljelykselle v. 1928 ja ojitettu avo-ojilla $20 \mathrm{~m}: \mathrm{n}$ sarkoihin. Koe on sijoitettu kahdelle saralle. Se aloitettiin v. 1930 , jolloin saveus $\left(100 \mathrm{~m}^{3} / \mathrm{ha}\right)$ suoritettiin ensimmäisen kerran ja kalkitut koejäsenet kalkittiin käyttäen $2000 \mathrm{~kg} /$ ha sammutettua kalkkia. Kalkitus uudistettiin v. $1937 \mathrm{käyt-}$ täen $2000 \mathrm{~kg} /$ ha kalkkikivijauhetta; samoin saveus v. $1942\left(200 \mathrm{~m}^{3} / \mathrm{ha}\right)$.

Muokkaus ja muut hoitotoimenpiteet on suoritettu samalla tavalla kuin talousviljelyksillä.

\section{Koesuunnitelma on seuraava:}

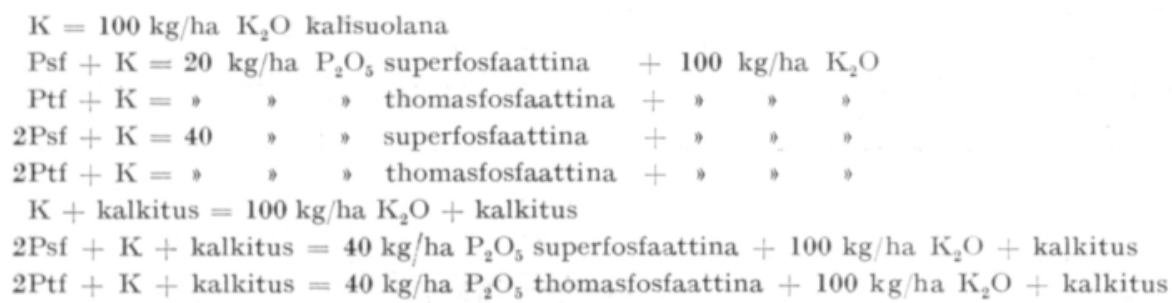

Käytetyt thomasfosfaattimäärät sisälsivät sitruunahappoon liukenevaa $\mathrm{P}_{2} \mathrm{O}_{5}$ :ttä yhtä paljon kuin vertailtavat superfosfaattimäärät ammoniumsitraattiin liukenevaa $\mathrm{P}_{2} \mathrm{O}_{5}: t$ tä. V. 1948 koealueen ollessa 3. vuoden nurmena koesuunnitelmaa muutettiin siten, että thomasfosfaatti korvattiin vastaavalla määrällä hienofosfaattia. V. 1941 ei fosfaattilannoitusta annettu ollenkaan ja kalilannoituskin oli vain $60 \mathrm{~kg} / \mathrm{ha} \mathrm{K}_{2} \mathrm{O}$. Vuosilta 1943 ja 1944 ei ole koetuloksia käytettävissä. Kaikki koejäsenet ovat saaneet vuosittain $100 \mathrm{~kg} / \mathrm{ha} \mathrm{K}_{2} \mathrm{O} 40$ tai $48 \%$ :na kalisuolana. Typpilannoitteita ei ole annettu.

Koevuosien sääolot ilmenevät Píssın (3) tutkimuksesta.

Kokeen vuotuiset satotulokset esitetään liitetaulukossa I. 


\section{Nurmet}

Taulukosta 1 näkyy, että superfosfaatti on ollut selvästi thomas- ja hienofosfaattia parempi. Ero on kaksinkertaisia fosfaattimääriä käytettäessä ollut selvempi kuin yksinkertaisilla määrillä ja erittäin selvä kalkitulla koealueella.

Taulukko 1. Keskimääräiset heinäsadot vuotta kohden $\mathrm{kg} / \mathrm{ha}$ (20 vuotta). Ensimmäisenä 10-vuotiskautena käytetty thomasfosfaattia ja toisena hienofosfaattia.

Table 1. Average annual yields of hay in $\mathrm{kg}$ per ha (during 20 years). During 10 years one phosphate component basic slag and during 10 years hyperphosphate.

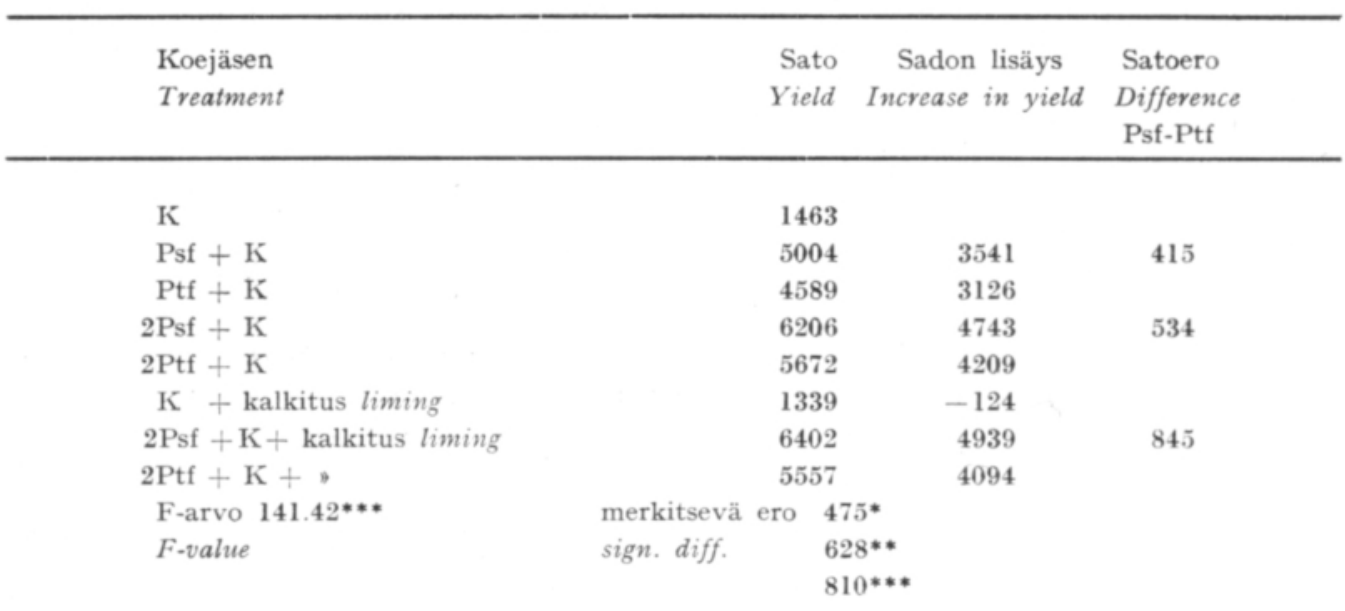

Taulukon 2 mukaan superfosfaatti on ollut thomasfosfaattia parempi, mutta erot ovat niin pieniä, että ne mahtuvat virherajoihin.

Taulukko 2. Keskimääräiset heinäsadot $\mathrm{kg} / \mathrm{ha}$ (10 vuotta). Superfosfaatin ja thomasfosfaatin vertailu.

Table 2. Average annual yields of hay in $\mathrm{kg}$ per ha (during 10 years). One phosphate component basic slag.

\begin{tabular}{|c|c|c|c|}
\hline $\begin{array}{l}\text { Koejäsen } \\
\text { Treatment }\end{array}$ & $\begin{array}{r}\text { Sato } \\
\text { Yield }\end{array}$ & $\begin{array}{c}\text { Sadon lisäys } \\
\text { Increase in yield }\end{array}$ & $\begin{array}{l}\text { Satoero } \\
\text { Difference } \\
\text { Psf-Ptf }\end{array}$ \\
\hline K & 1473 & & \\
\hline Psf $+\mathbf{K}$ & 4841 & 3368 & 454 \\
\hline $\mathbf{P t f}+\mathbf{K}$ & 4387 & 2914 & \\
\hline $2 \mathrm{Psf}+\mathrm{K}$ & 5284 & 4311 & 233 \\
\hline $2 \mathrm{Ptf}+\mathrm{K}$ & 5551 & 4078 & \\
\hline $\mathrm{K}+$ kalkitus liming & 1251 & -222 & \\
\hline $2 \mathrm{Psf}+\mathrm{K}+$ kalkitus liming & 5759 & 4286 & 488 \\
\hline $2 \mathrm{Ptf}+\mathrm{K}+$ & 5271 & 3798 & \\
\hline F-arvo $55.90 * *$ & merkitsevä ero 707 & & \\
\hline \multirow[t]{2}{*}{ F-value } & sign. diff. $\quad 940$ & $* *$ & \\
\hline & & & \\
\hline
\end{tabular}


Taulukon 3 mukaan superfosfaatti on ollut 2P-määrillä selvästi hienofosfaattia parempi. Kalkitulla alueella superfosfaatin paremmuus on erittäin selvä.

Taulukko 3. Keskimääräiset heinäsadot $\mathrm{kg} / \mathrm{ha}(10$ vuotta). Superfosfaatin ja hienofosfaatin vertailu.

Table 3. Average annual yields of hay in $\mathrm{kg}$ per ha (during 10 years). One phosphate component hyperphosphate.

\begin{tabular}{|c|c|c|c|}
\hline Koejäsen & Sato & Sadon lisäys & Satoero \\
\hline Treatment & Yield & Increase in yield & $\begin{array}{c}\text { Difference } \\
\text { Psf-Phf }\end{array}$ \\
\hline
\end{tabular}

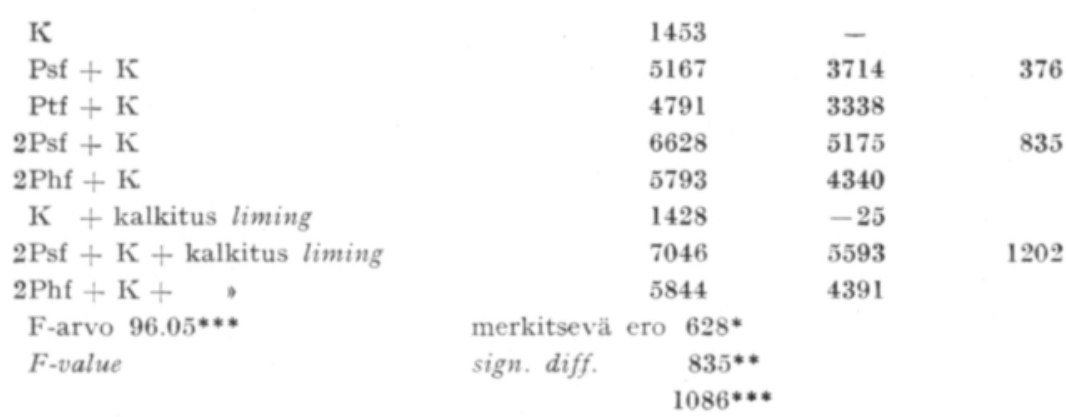

Taulukon 2 ja 3 perusteella ei voida kuitenkaan arvostella thomasfosfaatin ja hienofosfaatin paremmuutta toisiinsa verrattuna, koska hienofosfaatti levitettiin ensi kerran kolmannen vuoden nurmelle ja nurmi pidettiin 12 vuoden ikäiseksi. Siten hienofosfaatti ei tullut koskaan mullatuksi. Sitäpaitsi thomasfosfaatin jälkivaikutus voi vaikuttaa tuloksiin.

Taulukosta 4 havaitaan, että 12 vuoden kuluessa ei fosfaattilannoitusta saaneilla koeruuduilla ole tapahtunut kokonaissadon alenemista. Sensijaan pelkällä kalilannoituksella on sadon aleneminen ollut nurmen iän lisääntyessä selvä.

Taulukko 4. Kaksitoistavuotisen heinänurmen sadot kolmivuotisjaksoittain kg/ha. Vuosina 1946 - 1948 annettu thomasfosfaattia, vuosina 1949-1957 hienofosfaattia.

Table 4. The average yields $\mathrm{kg}$. per ha of 12 years old ley in 3-year periods. During the years 1946-1948 one phosphate component basic slag, during the years 1949-1957 hyperphosphate.

\begin{tabular}{|c|c|c|c|c|}
\hline \multirow{3}{*}{$\begin{array}{l}\text { Koejäsen } \\
\text { Treatment }\end{array}$} & \multirow{2}{*}{\multicolumn{4}{|c|}{$\begin{array}{l}\text { Heinäsato kolmivuotisjaksoittain } \\
\text { The yield of hay in periods of } 3 \text { years }\end{array}$}} \\
\hline & & & & \\
\hline & $1946-1948$ & $1949-1951$ & $1952-1954$ & $1955-1957$ \\
\hline K & 1900 & 1983 & 1462 & 885 \\
\hline Psf $+\mathrm{K}$ & 5550 & 5196 & 4566 & 5534 \\
\hline $\mathrm{Ptf}+\mathrm{K}$ & 4409 & 4710 & 4320 & 5529 \\
\hline $2 \mathrm{Psf}+\mathbf{K}$ & 5964 & 7319 & 5708 & 6731 \\
\hline $2 \mathrm{Ptf}+\mathrm{K}$ & 4739 & 6373 & 5029 & 6379 \\
\hline $\mathrm{K}+$ kalkitus liming & 1621 & 1766 & 1368 & 1051 \\
\hline 2 Psf $+\mathrm{K}+$ kalkitus liming & 5053 & 7779 & 6291 & 7150 \\
\hline $2 \mathrm{Ptf}+\mathrm{K}+$ & 3779 & 5619 & 5339 & 7295 \\
\hline
\end{tabular}




\section{Viljat ja vihantarehu}

Koealueilla on kauraa viljelty ainoastaan 4 vuotena. Kevätvehnää ja vihantarehua kumpaakin yhtenä vuotena. Taulukosta 5 selviää, että super- ja thomasfosfaàtti ovat olleet samanarvoisia kauran lannoitteina. Tähän vaikuttanee se, että ne on mullattu maahan. Sama ilmenee myös liitetaulukossa esitetyistä kevätvehnän ja vihantarehun sadoista.

Taulukko 5. Keskimääräiset kauran jyvä- ja olkisadot kg/ha (4 vuotta). Superfosfaatin ja thomasfosfaatin vertailu.

Table 5. Average crop and straw yields of oats in $\mathrm{kg}$ per ha (during 4 years). One phosphate component basic slag.

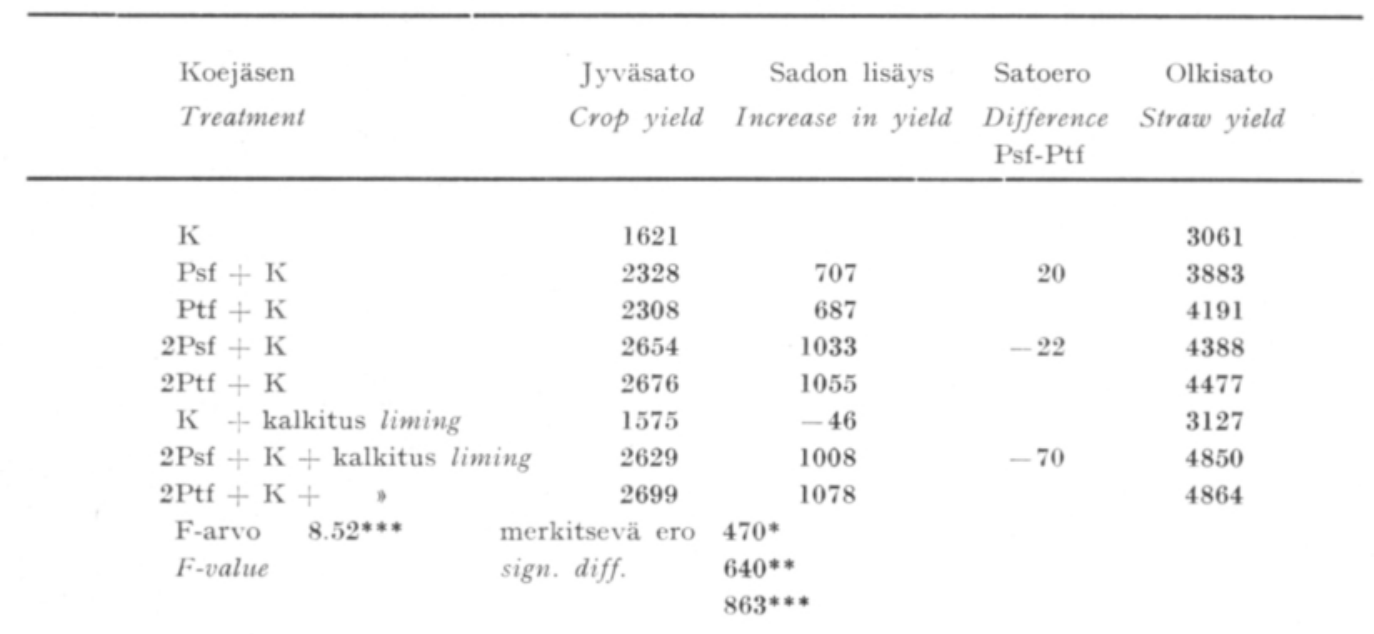

\section{Yhdistelmä kaikkien koekasvien sadoista}

Suoritettaessa tulosten tarkastelua rehuyksikköarvojen perusteella on ryarvoina käytetty: heinä 0.4 , kaura 0.8 , vehnä 1.0 , oljet 0.27 , vihantarehu, kuivattuna 0.4 .

Taulukosta 6 selviää, että koko koeajan kuluessa heinävaltaisessa viljelyksessä superfosfaatti on kalkitulla koealueella antanut parempia satoja, mutta kalkitsemattomalla koealueella erot ovat niin pieniä, että ne jäävät virherajojen sisälle.

\section{Kalkituksen vaikutus}

Taulukosta 6 selviää, että kalkitus ei tässä kokeessa ole aiheuttanut varmoja satoeroja puoleen eikä toiseen. Leteensuon koeaseman mutasuot ovat luonnostaan niin kalkkirikkaita, ettei niillä ole muissakaan kalkituskokeissa saavutettu sadon lisäyksiä (4). 
Taulukko 6. Koekasvien keskimääräiset vuotuiset sadot ry/ha 26 vuoden kuluessa.

Table 6. Average annual crop yields of all experimental plants during 26 years, food units per ha.

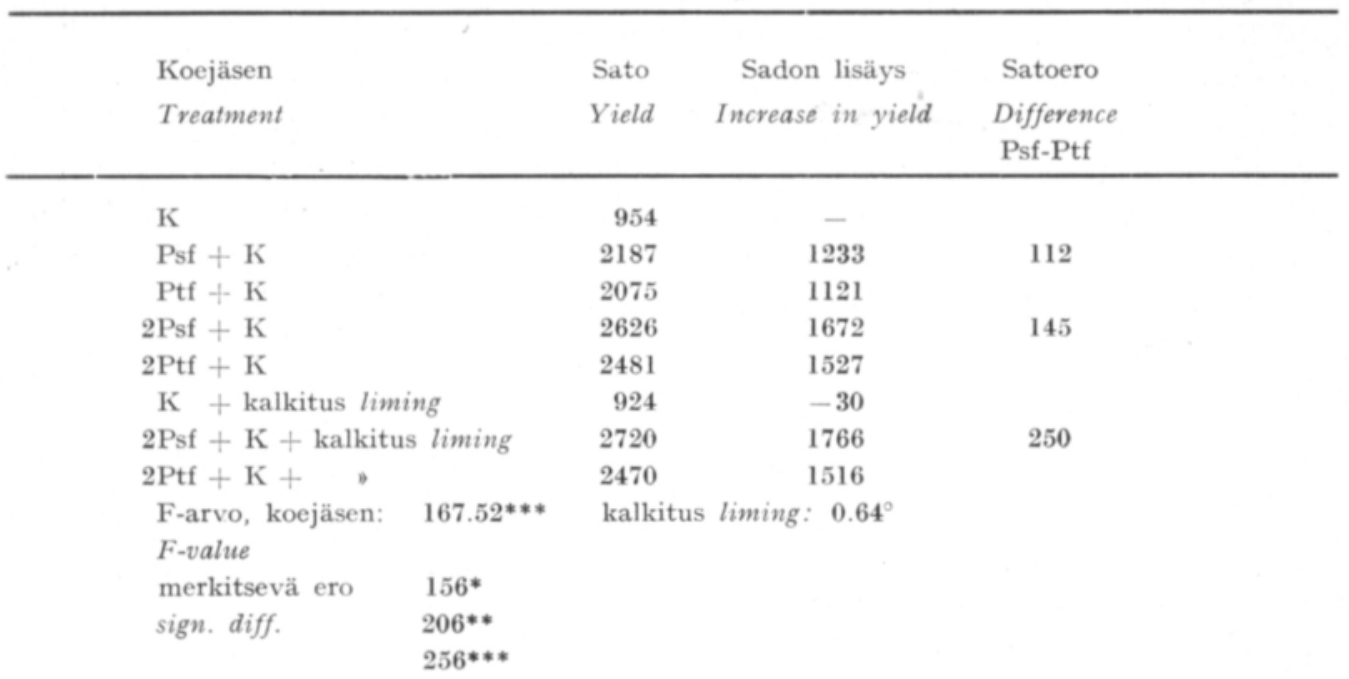

\section{Sadon laatu}

Suoritetun heinäanalyysin mukaan (taulukko 7) timotein määrä on vaihdellut 12. vuoden nurmessa fosfaattilannoituksen saaneilla ruuduilla 53.8 -86.1 $\%$ :iin. Ruuduilla, jotka ovat saaneet pelkän kalilannoituksen, on heinän timoteipitoisuus ollut vähäinen. Heinän timoteipitoisuus on ollut sekä superfosfaattia että hienofosfaattia saaneilla ruuduilla suunnilleen samaa suuruusluokkaa. Kalkitus näyttää edistäneen timotein säilymistä nurmessa.

Taulukko 7. 12. vuoden nurmen botaaninen koostumus.

Table 7. The botanical composition of 12 th year ley.

\begin{tabular}{cccc}
\hline Koejäsen & Timoteita & Muita hyötykasveja & Rikkaruohoja \\
Treatment & Timothy & Other cultivated plants & Weeds \\
& $\%$ & $\%$ & $\%$ \\
\hline $\mathrm{K}$ & & & \\
$\mathrm{Psf}+\mathrm{K}$ & 1.9 & 0.1 & 98.0 \\
$\mathrm{Ptf}+\mathrm{K}$ & 53.8 & 2.6 & 43.6 \\
$2 \mathrm{Psf}+\mathrm{K}$ & 65.9 & 4.5 & 29.6 \\
$2 \mathrm{Ptf}+\mathrm{K}$ & 69.8 & 2.5 & 34.4 \\
$\mathrm{~K}+\mathrm{kalkitus} \mathrm{liming}$ & 64.3 & 1.3 & 96.2 \\
$2 \mathrm{Psf}+\mathrm{K}+$ kalkitus liming & 3.7 & 0.1 & 14.9 \\
$2 \mathrm{Ptf}+\mathrm{K}+$ kalkitus liming & 80.1 & 5.0 & 10.8
\end{tabular}

Muiden hyötykasvien ryhmässä tavattiin pääasiassa nurminataa (Festuca pratensis) ja niittynurmikkaa (Poa pratensis). Rikkaruohojen ryhmässä oli PK- 
lannoituksen saaneilla ruuduilla pääasiassa juolavehnää (Agropyrum repens), kun taas K-lannoituksen saaneilla ruuduilla valtarikkaruohoina olivat nurmirölli (Agrostis tenuis) ja aronata (Festuca rubra).

KAILA (1) on suorittanut 12. vuoden nurmen sadosta tutkimuksia ja todennut, että käytetyn fosfaatțilannoituksen määrällä ja laadulla on ratkaiseva vaikutus heinän fosforipitoisuuteen. Niinpä $200 \mathrm{~kg}$ :lla superfosfaattia saadun heinän fosforipitoisuus oli huomattavasti korkeampi kuin $100 \mathrm{~kg}$ :lla saadun. Erittäin suuret erot olivat hienofosfaattia ja superfosfaattia saaneiden koejäsenten heinän fosforipitoisuudessa: edellisissä noin $0.14-0.15 \% P$ ja jälkimmäisissä noin $0.21-0.23 \%$ $P$. Ei ole tietoa, olisiko vilja-, juurikasvi- ja perunasatojen fosforipitoisuudessa sama suhde.

\section{$P \ddot{a} \ddot{a}$ tel $m \ddot{a} t$}

Kokeen perusteella voitaneen tehdä seuraavia päätelmiä:

Superfosfaatti ja thomasfosfaatti ovat viljanviljelyssä vaikutukseltaan samanarvoisia.

Nurmen pintalannoitukseen on superfosfaatti soveliaâmpaa kuin thomas- ja hienofosfaatti.

Vuosittain uudistetulla sopivalla fosfaatti-kali pintalannoituksella voidaan timoteinurmen ikää lisätä sadon määrän ja laadun silti huonontumatta. Nurmen iän lisääntyessä saattaa siihen ilmaantua kuitenkin rikkaruohoja, etenkin juolavehnää.

KIRJALLISUUTTA:

(1) KAILA, A. 1958. Effect of various kinds of phosphorus fertilizers on peat soil. Maat. tiet. aikak. 30: $213-222$.

(2) LindBerG, H. 1903. Leteensuon kasvillisuus. S. suovilj. yhd. vuosik. 1903: 264-270.

(3) PESSI, Y. 1959. Kivennäismaan vaikutuksesta rahkasuon maanparannusaineena Leteensuon koeaseman pitkäaikaisten kenttäkokeiden perusteella. Summary: On the effect of mineral soil as a soil improving agent on Sphagnum bogs on the basis of prolonged field tests at Leteensuo Experimental Station. Acta agr. fenn. 94. 14: 241-268.

(4) - - 1959. Mutasuon kalkituskokeiden tuloksia Leteensuolta. Summary: The results of liming tests on fen at Leteensuo. Maat. tiet. aikak. 31: 285-293.

(5) Rindell, A. 1903. Geologisessa mielessä huomattava tulos Leteensuon tutkimisesta. S. suovilj. yhd. vuosik. 1903: 271-275. 
S U M M A R Y :

ON THE EFFECTS OF SUPERPHOSPHATE, BASIC SLAG AND HYPERPHOSPHATE ON FEN SOIL

\section{MAURI TAKALA}

Society of Peat Cultivation, Experiment Station Leteensuo

At Leteensuo Experiment Station a test to compare the effects of superphosphate and basic slag on fen soil was started in 1930 .

The peat on the test area is fairly well humified forest sedge peat. The thickness of the peat layer is more than 1 metre. The test area was reclaimed in 1928 and ditched so that the strips between ditches are 20 metres broad. The test area was clayed in $1930\left(100 \mathrm{~m}^{3} / \mathrm{ha}\right)$ and in $1942\left(200 \mathrm{~m}^{3} / \mathrm{ha}\right)$. The test areas which were limed were treated with slaked lime $(2000 \mathrm{~kg} / \mathrm{ha})$ in 1930 and with limestone powder $(2000 \mathrm{~kg} / \mathrm{ha})$ in 1937 . Basic slag was applied in amounts containing citric acid soluble $\mathrm{P}_{2} \mathrm{O}_{5}$ as much as superphosphate contained ammonium citrate soluble $\mathrm{P}_{2} \mathrm{O}_{5}$. In 1948 when the test area was $3 \mathrm{rd}$ year ley the trial plan was changed so that basic slag was replaced by the corresponding amount of hyperphosphate. In 1941 no phosphate dressing was applied, and potassium dressing was only $60 \mathrm{~kg} / \mathrm{ha} \mathrm{K}_{2} \mathrm{O}$. From the years 1943 and 1944 no test results are available.

According to the test results the effect of superphosphate and basic slag are equal in cultivating cereals. As cover dressing for ley superphosphate is more suitable than basic slag or hyperphosphate. By means of appropriate cover dressing with phosphate and potassium it is possible to lenghten the age of timothy ley without impairment of crop quantity or quality. While the age of timothy ley lengthens, weeds, especially quick grass, may appear. 


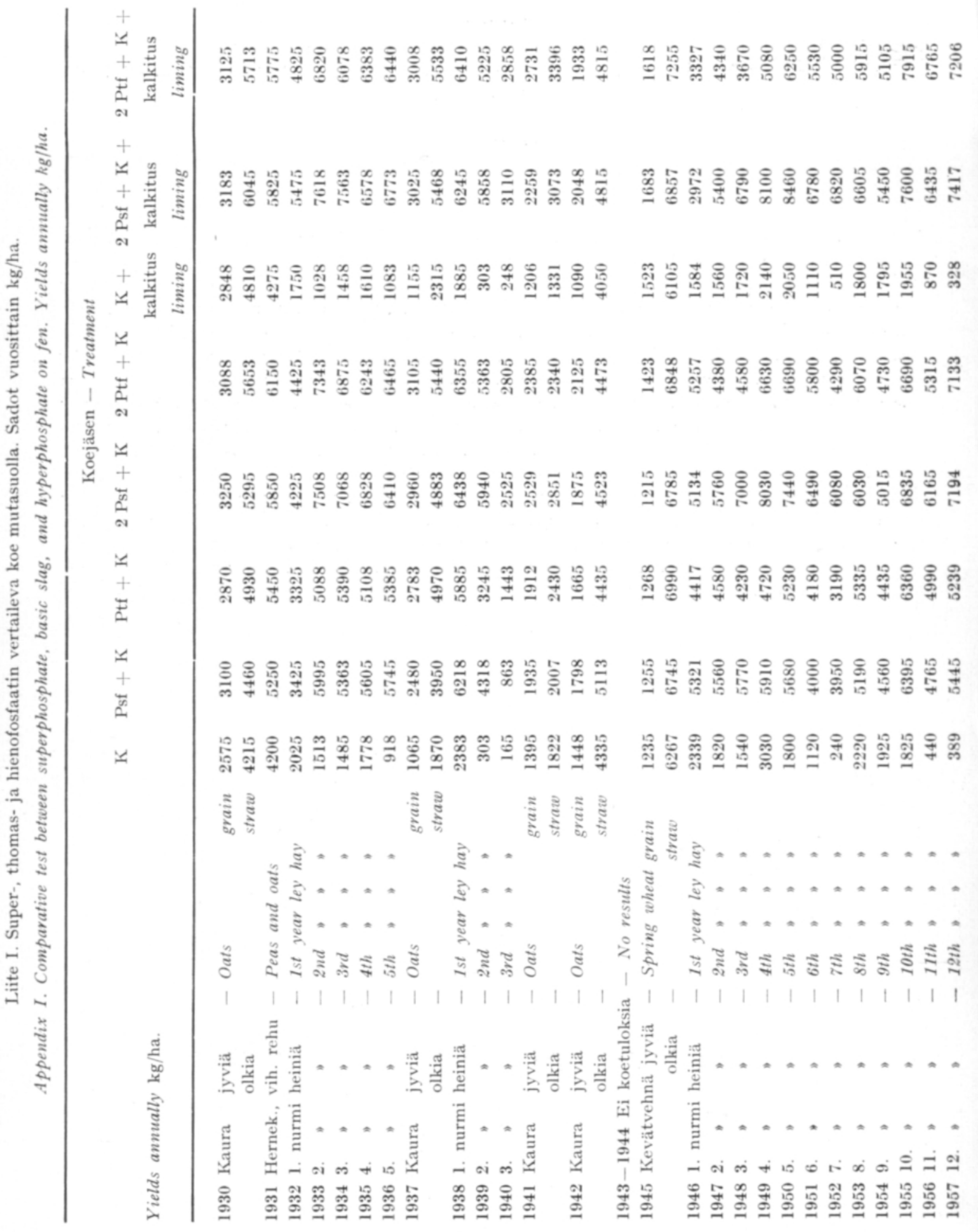

